\title{
RANCANG BANGUN APLIKASI AUGMENTED REALITY KATALOG BARANG ELEKTRONIK BERBASIS ANDROID MENGGUNAKAN UNITY 3D
}

\author{
Agus Sugiharto
}

\begin{abstract}
E-Catalog (electronic catalog) is a list that contains information and is made electronically. $E$ Catalog is one of the most developed concepts in the world of information technology. This development brought many changes to the sector of business activity which had been carried out in the real world. The change was marked by the existence of a number of efforts from the business activity sector which was originally based in the real world (real), then developed it into the virtual world (virtual). One example of using augmented reality is advertising media. If we watch a football match often seen ads run on the screen at the edge of the field. Actually the advertisement did not happen or was actually displayed on the stadium, only television viewers saw it. This is because the television station is adding the image of the ad as a virtual object on the football broadcast it receives. Another example is making a film or news program on television such as weather news where the host appears to be on a map to show the weather forecast to be delivered. The term is a green screen or green screen, which is by using a large green background screen, we can replace the background with another display digitally. The military has for years been using augmented reality technology in the form of a cockpit display that displays information to pilots on the cockpit protective glass or the windshield of their flight helmets. Augmented Reality has been widely used in the world of entertainment, business, medical, design and engineering, robotics and telerobotics, manufacturing, education, etc. There are many more uses of AR technology in everyday life. Developers try various modifications to create tools that can combine the real world and cyberspace with benefits that can be felt more by its users.

Key Words: Augmented Reality, Unity 3D, Electronic Goods, Android
\end{abstract}

\section{PENDAHULUAN}

E-Catalogue (katalog elektronik) adalah suatu daftar yang berisi informasi dan dibuat secara elektronik. ECatalogue merupakan salah satu konsep yang sangat berkembang dalam dunia teknologi informasi. Perkembangan ini membawa banyak perubahan terhadap sektor aktivitas bisnis yang selama ini dijalankan di dunia nyata. Perubahan tersebut ditandai dengan adanya sejumlah upaya dari sektor aktivitas bisnis yang semula berbasis di dunia nyata (real), kemudian mengembangkannya ke dunia maya (virtual).
Salah satu contoh penggunaan augmented reality adalah sebagai media iklan. Jika kita menonton sebuah pertandingan sepakbola sering terlihat iklan berjalan pada layar dipinggir lapangan. Sebenarnya iklan itu tidak terjadi atau terpampang secara nyata di stadion tersebut, hanya penonton televisi saja yang melihatnya. Ini dikarenakan stasiun televisilah yang menambahkan gambar iklan tersebut sebagai objek maya pada siaran sepakbola yang diterimanya. Contoh lainnya adalah pembuatan film atau acara berita di televisi seperti berita cuaca dimana sang pembawa acara 
terlihat seperti berada diatas sebuah peta untuk menunjukan prakiraan cuaca yang akan disampaikan. Istilahnya adalah layar hijau atau green screen, yaitu dengan menggunakan latar belakang layar besar berwarna hijau polos, kita dapat mengganti latar belakang tersebut dengan tampilan lain secara digital.

\section{LANDASAN TEORI}

\subsection{PENGERTIAN} INFORMASI

Pengertian sistem menurut Jugianto (2005:2) mengemukakan bahwa sistem adalah kumpulan dari elemenelemen yang berinteraksi untuk mencapai suatu tujuan tertentu. Sistem ini menggambarkan suatu kejadian-kejadian dan kesatuan yang nyata yang merupakan suatu suatu objek nyata, seperti tempat, benda, dan orang yang betul-betul ada dan terjadi.

Jenis sistem informasi berbedabeda yang masing-masing dirancang untuk kebutuhan yang khusus yaitu :

a. Sistem Single - user dan Workstation.

b. Sistem Multiuser.

c. Sistem server jaringan.

d. Sistem Waktu Nyata.

e. Sistem Kendali Embedded.

f. Sistem terdistribusi. "Menurut (Janner Simarmata, 2006:63).

\subsection{Defenisi Informasi}

Informasi menurut Azhar Susanto (2005:46) dalam bukunya Sistem Informasi Akuntansi mendefenisikan informasi sebagai berikut "Informasi adalah hasil pengolahan data yang memberikan arti dan manfaat".

Informasi menurut Jugianto (2005:8) dalam bukunya yang berjudul Analisis dan Desain Sistem Informasi bahwa "Informasi adalah data yang diolah menjadi bentuk yang lebih berguna bagi yang menerimanya".

Berdasarkan penjelasan diatas penulis dapat menyimpulkan bahwa informasi adalah serangkaian data yang telah terorganisasi yang mempunyai sifat sementara, tergantung dengan waktu dan manfaat bagi penerimanya.

\subsection{Defenisi Sistem Informasi}

Sistem menurut Al-Bahra (2005:13) dalam bukunya yang berjudul Analisis dan Desain Sistem Informasi menjelaskan bahwa "suatu sistem yang dibuat oleh manusia yang terdiri dari komponen-komponen dalam organisasi untuk mencapai suatu tujuan yaitu menyajikan informasi”.

Sistem Informasi menurut Azhar Susanto (2005:55) dalam bukunya yang berjudul Sistem Informasi Akuntansi Konsep dan Pengembangan Berbasis Komputer menjelaskan bahwa "sistem informasi adalah kumpulan dari sub-sub sistem baik fisik maupun non fisik yang saling berhubungan satu sama lain dan bekerja secara harmonis untuk satu tujuan yaitu mengolah data menjadi informasi yang berarti dan berguna.

Sistem Informasi adalah suatu sistem yang menyediakan suatu informasi dalam organisasi yang mampu melaksanakan kebutuhan transaksi harian, untuk mendukung operasi yang bersifat manajerial dan kegiatan strategi dari suatu organisasi, serta mampu menyediakan laporan-laporan yang perlukan. Pada prinsipnya sistem informasi mempunyai tiga peranan utama yaitu :

a. Menunjang kegiatan operasional.

b. Menunjang manajemen dalam pengambilan keputusan. 
c. Menunjang keunggulan strategi kompetitif organisasi.

\subsection{AUGMENTED REALITY}

Augmented reality adalah teknologi yang menggabungkan benda maya dua dimensi dan ataupun tiga dimensi ke dalam sebuah lingkungan nyata tiga dimensi lalu memproyeksikan bendabenda maya tersebut dalam waktu nyata (real time) (Putra, 2012). Sejarah augmented reality dimulai dari tahun 1957-1962, ketika seorang penemu yang bernama Morton Heilig, seorang sinematografer, menciptakan dan mempatenkan sebuah simulator yang disebut Sensorama dengan visual, getaran dan bau. Pada tahun 1966, Ivan Sutherland menemukan head-mounted display yang diclaimnya adalah, jendela ke dunia virtual.

\section{"Pada Tahun 1994, Milgram dan Kishino merumuskan kerangka kemungkinan penggabungan dan peleburan dunia nyata dan dunia maya ke dalam sebuah kontinuum virtualitas. Sisi yang paling kiri adalah lingkungan nyata yang hanya berisi benda nyata, dan sisi paling kanan adalah lingkungan maya yang berisi benda maya" (Wirga, et al. 2012).}

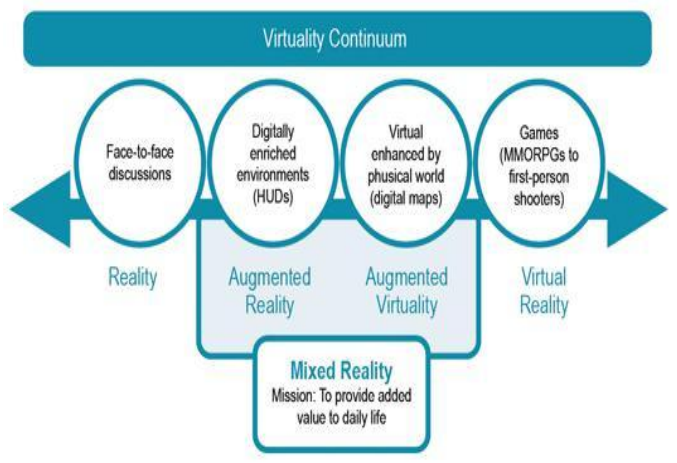

Gambar 1. Virtuality Contimuum oleh Milgram dan Kishino $\begin{array}{cr}\text { Pada gambar } 1 & \text { menjelaskan } \\ \text { bahwa dalam realitas tertambah }\end{array}$ (augmented reality), yang lebih dekat ke sisi kiri, lingkungan bersifat nyata dan benda bersifat maya, sementara dalam augmented virtuality atau virtualitas tertambah, yang lebih dekat ke sisi kanan, lingkungan bersifat maya dan benda bersifat nyata..

Tujuan dari augmented reality adalah mengambil dunia nyata sebagai dasar dengan menggabungkan beberapa teknologi virtual dan menambahkan data konstektual agar pemahaman manusia sebagai penggunanya menjadi semakin jelas. Data konstektual ini dapat berupa komentar audio, data lokasi, konteks sejarah, atau dalam bentuk lainnya. Pada saat ini, AR telah banyak digunakan dalam berbagai bidang seperti kedokteran, militer, manufaktur, hiburan, museum, game pendidikan, pendidikan, dan lain-lain (Rahmat, 2011).

\subsection{Metode Pelacakan (tracking) Augmented Reality}

Ada beberapa jenis metode pelacakan (tracking) pada AR, antara lain sebagai berikut:

a. Elektromagnetic tracking system, mengukur medan magnet yang dihasilkan melalui arus listrik yang secara simultan melewati tiga kumparan kabel yang disusun secara tegak lurus satu dengan yang lain. Setiap kumparan kecil bersifat elektromagnet. Sensor sistem mengkalkulasikan bagaimana medan magnet terbentuk dan pengaruhnya terhadap kumpuran lainnya. Pengukuran tersebut menunjukkan posisi atau orientasi dan arah dari emitter. Reponsibilitas dari efisiensi sistem pelacakan elektromagnet sangat baik dan tingkat latensinya 
cukup rendah. Satu kekurangan dari sistem ini adalah apapun yang dapat menghasilkan medan magnet dapat mempengaruhi sinyal yang dikirim ke sensor.

b. Accoustic tracking system, sistem pelacakan ini menangkap dan menghasilkan gelombang suara ultrasonic untuk mengidentifikasi orientasi dan posisi dari target. Sistem ini mengkalkulasi waktu yang digunakan suara ultrasonic untuk mencapai sensor. Sensor biasanya selalu menjaga kestabilan dalam lingkungan dimana pengguna menempatkan emitter. Bagaimanapun, kalkulasi dari orientasi serta posisi target bergantung pada waktu yang digunakan oleh suara untuk mencapai sensor adalah dilakukan oleh sistem. Terdapat banyak kekurangan pada sistem pelacakan acoustic. Suara yang lewat sangat lambat, sehingga tingkat update posisi target juga menjadi lambat

c. Optical tracking system, perangkat ini menggunakan cahaya untuk menghitung orientasi dan posisi target. Sinyal emitter dalam perangkat optical secara khusus terdiri atas sekumpulan LED inframerah. Sensor kamera dapat menangkap cahaya inframerah yang dipancarkan. LED menyala dalam pulse secara sekuensial. Kamera merekam sinyal pulse dan mengirim informasi kepada unit pemrosesan sistem. Unit tersebut kemudian dapat menghitung kemungkinan data untuk menentukan posisi dan orientasi target. Sistem optical mempunyai tingkat upload data yang cepat, sehingga latensi dapat diminimalisasi. Kekurangan sistem ini adalah penglihatan antara kamera dan LED dapat menjadi gelap, bertentangan dengan proses pelacakan. Radiasi inframerah juga dapat membuat sistem kurang efektif.

\subsection{Teknik Tampilan Augmented Reality}

Terdapat tiga teknik tampilan pada AR yaitu head-mounted display, handheld displays, dan spatial display.

\section{a. Head-mounted display}

Head-mounted display (HMD) menempatkan gambar diantara dunia nyata dan objek grafik virtual melalui pandangan user terhadap dunia nyata. Head-mounted display terbagi menjadi dua bagian yaitu optical see-through dan video see-through. Optical see-through biasanya menempatkan sebuah semisilvered mirror sebelum mata pengguna. Pengguna dapat melihat dunia nyata melalui mirror (cermin), dan juga melihat grafik komputer digambarkan pada layar miniatur yang tampak pada refleksi cermin. Proses ini mempunyai efek grafik seperti munculnya objek hitam transparan terhadap pengguna, memberikan pandangan tanpa modifikasi dari objek nyata pada tempat yang sama. Video seethrough, pandangan pengguna tidak secara langsung terhadap dunia nyata tetapi hanya sebuah miniatur hasil komputerisasi yang nampak penuh dalam layar. HMD harus melacak dengan sensor yang menyediakan 6DOF (six degrees of 33 freedom). Pelacakan ini membuat sistem dapat menyelaraskan virtual informasi ke dunia nyata.

\section{b. $\quad$ Handheld display}

Handheld display bekerja dengan sebuah layar kecil yang pas atau sesuai dengan genggaman pengguna. Handheld AR merupakan solusi untuk video-see through. Mulanya, teknik ini bekerja dengan penanda fiducial, dan kemudian 
GPS, dan sensor MEMS

(Microelectromechanical systems) seperti kompas digital, accelerometer, dan gyroscope. Saat ini, pelacakan tanpa marker, yaitu SLAM (Simultaneous localization and mapping) seperti PTAM yang mulai digunakan. Keuntungan utama dari handheld AR adalah mudah digunakan, dapat dibawa kemana-mana (portable) dan telah dilengkapi kamera.

\section{$2.7 \quad$ UNITY 3D}

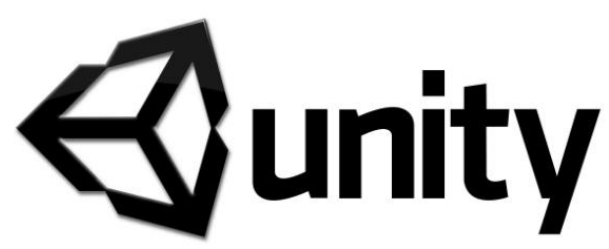

Gambar 2. Logo Unity

Unity merupakan suatu aplikasi yang digunakan untuk mengebangkan game multi platform yang didesain untuk mudah digunakan. Unity itu bagus dan penuh perpaduan dengan aplikasi yang professional. Editor pada unity dibuat dengan user interface yang sederhana. Editor ini dibuat setelah ribuan jam yang mana telah dihabiskan untuk membuatnya menjadi nomor satu dalam urutan ranking teratas untuk editor game. Grafis pada unity dibuat dengan grafis tingkat tinggi untuk OpenGL dan direct. Unity mendukung semua format file, terutamanya format umum seperti semuat format dari art applications. Unity cocok dengan versi 64-bit dan dapat beroperasi pada Mac OS x dan windows dan dapat menghasilkan game untuk Mac, Windows, Wii, iPhone, iPad dan Android.
Unity secara rinci dapat digunakan untuk membuat video game $3 \mathrm{D}$, real time animasi 3D dan visualisasi arsitektur dan isi serupa yang interaktif lainnya. Editor Unity dapat menggunakan plugin untuk web player dan menghasilkan game browser yang didukung oleh Windows dan Mac. Plugin web player dapat juga dipakai untuk widgets Mac. Unity juga akan mendukung console terbaru seperti Playstation 3 dan Xbox 360. Pada tahun 2010, telah memperoleh Tecnology Innovation Award yang diberikan oleh Wall Street Journal dan tahun 2009, Unity Tecnology menajadi 5 perusahaan game terbesar. Tahun 2006, menjadi juara dua pada Apple Design Awards.

Server asset dari Unity dapat digunakan semua scripts dan aset game sebagai solusi dari versi control dan dapat mendukung proyek yang terdiri atas banyak gigabytes dan ribuan dari file multi-megabyte. Editor Unity dapat menyimpan metadata dan versi mereka, itu dapat berjalan, pembaharuan dan didalam perbandingan versi grafis. Editor Unity dapat diperbaharui dengan sesegera mungkin seperti file yang telah dimodifikasi. Server aset Unity juga cocok pada Mac, Windows dan Linux dan juga berjalan pada PostgresSQL, database server open source.

\subsection{ANDROID}

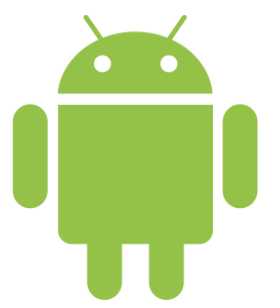

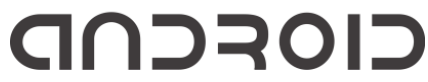

Gambar 3: Logo Android 
Android adalah sistem operasi berbasis Linux yang dirancang untuk perangkat seluler layar sentuh seperti telepon pintar dan komputer tablet. Android awalnya dikembangkan oleh Android, Inc., dengan dukungan finansial dari Google, yang kemudian membelinya pada tahun 2005. Sistem operasi ini dirilis secara resmi pada tahun 2007, bersamaan dengan didirikannya Open Handset Alliance, konsorsium dari perusahaan-perusahaan perangkat keras, perangkat lunak, dan telekomunikasi yang bertujuan untuk memajukan standar terbuka perangkat seluler.

Saat ini sudah banyak platform untuk perangkat selular, termasuk di dalamnya Symbian, iOS, Windows Mobile, BlackBerry, Java Mobile Edition, Linux Mobile (LiM), dan banyak lagi. Namun ada beberapa hal yang menjadi kelebihan Android. Walaupun beberapa fitur-fitur yang ada telah muncul sebelumnya pada platform lain, Android adalah yang pertama menggabungkan hal seperti berikut:

a. Keterbukaan, Bebas pengembangan tanpa dikenakan biaya terhadap sistem karena berbasiskan Linux dan open source. Pembuat perangkat menyukai hal ini karena dapat membangun platform yang sesuai yang diinginkan tanpa harus membayar royalti. Sementara pengembang software menyukai karena Android dapat digunakan diperangkat manapun dan tanpa terikat oleh vendor manapun.

b. Arsitektur komponen dasar Android terinspirasi dari teknologi internet mashup. Bagian dalam sebuah aplikasi dapat digunakan oleh aplikasi lainnya, bahkan dapat diganti dengan komponen lain yang sesuai dengan aplikasi yang dikembangkan.

c. Banyak dukungan service, kemudahan dalam menggunakan berbagai macam layanan pada aplikasi seperti penggunaan layanan pencarian lokasi, database SQL, browser dan penggunaan peta. Semua itu sudah tertanam pada Android sehingga memudahkan dalam pengembangan aplikasi.

\subsection{STRUKTUR NAVIGASI}

Struktur navigasi adalah struktur atau alur dari suatu program. Menentukan struktur navigasi merupakan hal yang sebaiknya dilakukan sebelum membuat suatu aplikasi. Ada 4 (empat) macam bentuk dasar dari struktur navigasi yang biasa digunakan dalam proses pembuatan aplikasi, yaitu :

\section{a. Struktur Navigasi Linier}

Struktur navigasi linier hanya mempunyai satu rangkaian cerita yang berurut, yang menampilkan satu demi satu tampilan layar secara berurut menurut urutannya. Tampilan yang dapat ditampilkan pada struktur jenis ini adalah satu halaman sebelumnya atau satu halaman sesudahnya, tidak dapat dua halaman sebelumnya atau dua halaman sesudahnya.

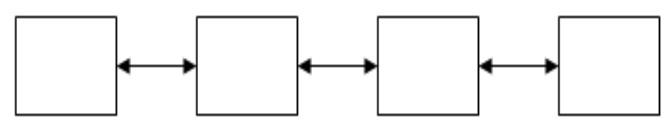

Gambar 4: Struktur Navigasi Linier

\section{b. Struktur Navigasi Hirarki}

Struktur navigasi hirarki biasa disebut struktur bercabang, merupakan suatu struktur yang mengandalkan percabangan untuk menampilkan data 
berdasarkan kriteria tertentu. Tampilan pada menu satu akan disebut sebagai Master Page (halaman utama pertama), halaman utama ini mempunyai halaman utama ini mempunyai halaman percabangan yang disebut Slave Page (halaman pedukung). Jika salah satu halaman pendukung dipilih atau diaktifkan, maka tampilan tersebut akan bernama Master Page (halaman utama kedua) dan seterusnya. Pada navigasi ini tidak diperkenalkan adanya tampilan secara linier.

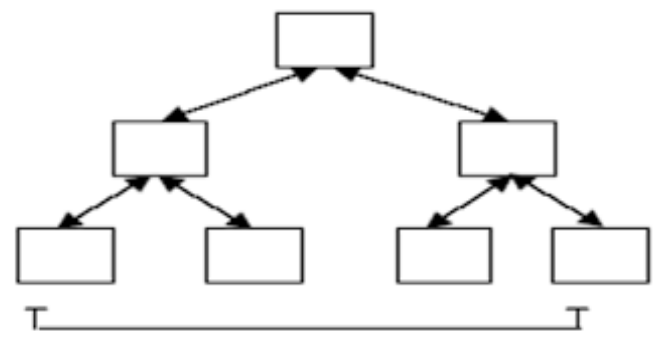

Gambar 5: Struktur Navigasi Hirarki

\section{c. Struktur Navigasi Non - Linier}

Struktur navigasi Non - Linier merupakan pengembangan dari struktur navigasi linier. Pada struktur ini diperkenalkan membuat navigasi bercabang. Percabangan pada struktur non linier ini berbeda dengan percabangan pada struktur hirarki. Karena pada percabangan ini walaupun terdapat percabangan, tetapi tiap - tiap tampilan mempunyai kedudukan yang sama yaitu tidak ada Master Page dan Slave Page.

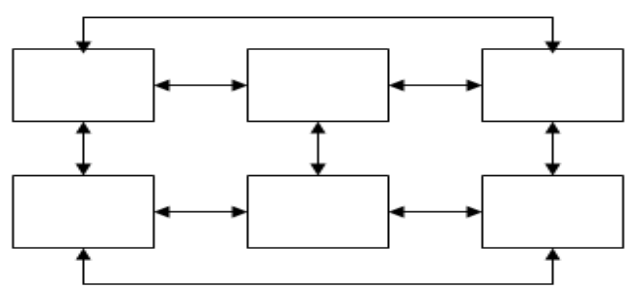

Gambar 6: Navigasi Non - Linier

\section{d. Struktur Navigasi Composite (Campuran)}

Struktur navigasi composite (campuran) disebut juga struktur navigasi bebas yang merupakan gabungan dari ketiga struktur yang ada. Struktur navigasi ini biasa digunakan dalam pembuatan multimedia karena dapat memberikan kerinteraksian yang lebih tinggi.

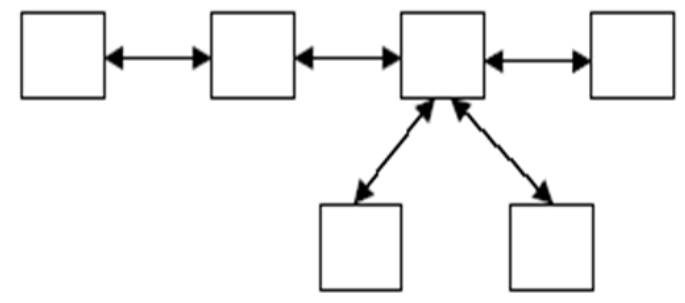

Gambar 7: Struktur Navigasi

Gambar 7 Struktur Navigasi Composite (Campuran)

\section{III.. METODE PENELITIAN}

Metode penelitian yang digunakan adalah menggunakan metode SDLC (System Development Life Cycle). Metode SDLC menggunakan pendekatan system yang disebut dengan Incramental Model Approach yang merupakan pengembangan sistem pada software, dan berdasarkan requirment software yang dipecah menjadi beberapa fungsi atau bagian sehingga model pengembangannya secara bertahap. Dilain pihak ada yang mengartikan model incramental ini sebagai perbaikan dari model waterfall. Model ini memiliki beberapa tahapan tahapan untuk pembuatan perangkat lunak yang dikerjakan secara berurut.

Tahap - tahap yang dilakukan dalam penelitian ini adalah : 


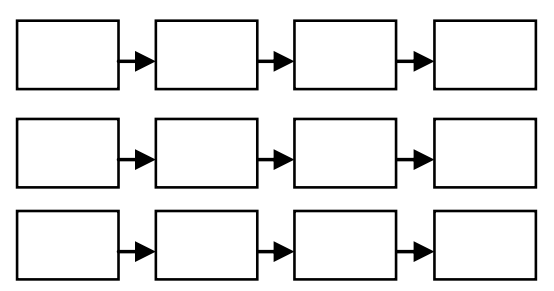

Gambar 8 Incramental Model Approach

1. Requirement.

Requirment adalah proses tahapan awal yang dilakukan pada incremental model adalah penentuan kebutuhan atau analisis kebutuhan.

2. Specification.

Specification adalah proses spesifikasi dimana menggunakan analisis kebutuhan sebagai acuannya.

3. Architecture Design.

Architecture Design adalah tahap selanjutnya, perancangan software yang terbuka agar dapat diterapkan sistem pembangunan per-bagian pada tahapan selanjutnya.

4. Code.

Tahap dimana setelah melakukan proses desain selanjutnya ada pengkodean.

5. Test.

Test merupakan tahap pengujian dalam model ini.

\subsection{TINJAUAN UMUM APLIKASI}

Aplikasi ini merupakan implementasi Augmented Reality sederhana yang diimplementasikan pada smartphone berbasis Android. Seperti aplikasi Augmented Reality pada umumnya, aplikasi ini membutuhkan marker/image target sebagai suatu input program dan menghasilkan output berupa objek 3-Dimensi dari setiap barang elektronik yang telah dipilih di menu. Objek 3-Dimensi alat elektronik tersebut bisa di rotasi dengan cara touch tombol Rotasi pada objek 3-Dimensi tersebut.

Hal yang pertama kali dilakukan adalah membuat objek 3D yang dibutuhkan dengan menggunakan Blender 2.79 serta menyiapkan tool pendukung untuk Augmented Reality, dan pembuatan buku sebagai alat peraga aplikasi Augmented Reality nantinya. Kemudian penulis melakukan pengumpulan data, baik berupa gambar, penjelasan, artikel, maupun jurnal dari internet yang berkaitan dengan aplikasi Augmented Reality. Aplikasi ini dibuat dengan menggunakan bahasa pemrograman C\# untuk Augmented Reality.

Aplikasi ini menggunakan marker sebagai penanda untuk menampilkan objek dalam bentuk 3D. Marker yang digunakan adalah gambar dari barangbarang elektonik yang nantinya akan dimunculkan objeknya. lalu pengguna akan melihat Augmented Reality setelah mengarahkan marker yang ada pada buah tersebut ke arah kamera yang nantinya kan menampilkan object 3D dari barang elektronik, dan menggunakan scene informasi yang akan menampilkan informasi spesifikasi dari barang tersebut.

Untuk dapat menggunakan aplikasi ini pengguna harus mempersiapkan marker terlebih dahulu, hanya marker yang sudah terdaftar di dalam data target marker saja yang dapat menghasilkan output objek 3D dari aplikasi ini. Secara umum dimulai dari pengambilan gambar marker dengan kamera atau webcam. Marker tersebut dikenali berdasarkan feature yang dimiliki, kemudian masuk ke dalam 
object tracker yang disediakan oleh Software Development Kit (SDK). Di sisi lain, marker tersebut telah didaftarkan dan disimpan ke dalam database. Object tracker selanjutnya akan melacak dan mencocokkan marker tersebut agar dapat menampilkan informasi yang sesuai. Hasil keluaran pelacakan marker segera ditampilkan ke dalam layar komputer dan layar ponsel cerdas. Informasi yang ditampilkan melekat pada marker bersangkutan secara real time seperti pada dibawah:

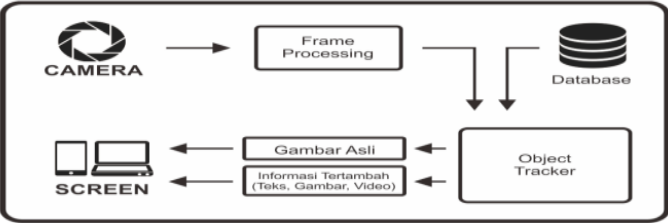

Gambar 9: Alur Kerja Aplikasi.

\subsection{RANCANGAN SKETSA \\ TAMPILAN APLIKASI}

Ada aplikasi ini terdapat 2 scene tampilan, yaitu scene splashscreen yang merupakan pembuka dan scene menu scene menu untuk memilih objek dan terdapat tombol Keluar untuk keluar dari aplikasi. Untuk memilih objek, tersedia 4 tombol utama yang masing-masing mewakili Mulai, Panduan, Tentang dan Keluar. Kemudian pada tombol mulai terdapat 10 tombol untuk memilih objek.

\subsubsection{Rancangan Splash Screen}

Tampilan

Tampilan splash screen adalah tampilan pembuka yang muncul saat aplikasi pertama dijalankan. Tampilan splash screen berisi gambar atau logo dari aplikasi katalog informa. Pada aplikasi katalog informa ini terdapat 2 splash screen, yaitu splash screen default dari Unity 3D dan splash screen yang dirancang sendiri. Seperti pada 3.5
Gambar Sketsa Tampilan splashscreen dibawah ini :

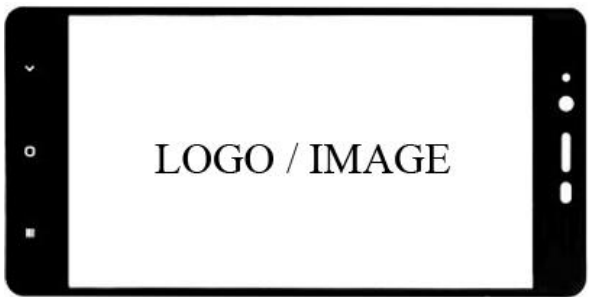

Gambar 10: Sketsa Tampilan SplashScreen

\subsubsection{Rancangan Tampilan Menu Utama}

Tampilan utama merupakan tampilan menu yang berisi 4 tombol yang setiap tombolnya mewakili tombol Mulai, Panduan, Tentang dan tombol Keluar. Pada menu ini, user bisa memilih tombol mulai untuk melihan pilihan objek, tombol panduan untuk melihat panduan, tombol tentang untuk melihat maksud dari aplikasi ini dan tombol keluar untuk keluar dari aplikasi. Seperti pada Gambar 3.3 Sketsa Tampilan Menu Utama dibawah ini :

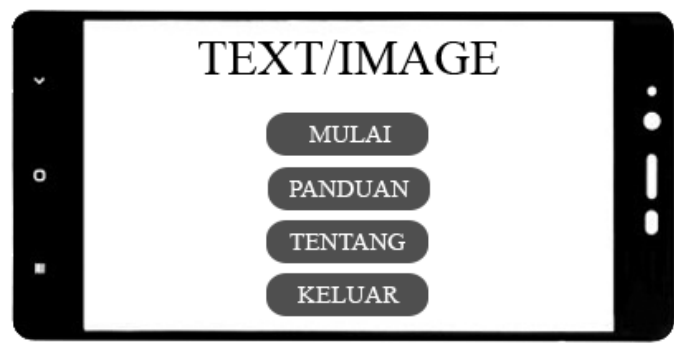

\section{Gambar 11: Sketsa Tampilan Utama} (Menu)

Penjelasan rancangan tampilan menu aplikasi Augmented Reality adalah sebagai berikut :
a. Mulai
Yaitu tampilan objek 3D Augmented Reality pilihan barang elektronik. 


\section{b. Panduan}

Yaitu menu bantuan cara menggunakan aplikasi AR ini.

\section{c. Tentang}

Yaitu keterangan tentang pengembang atau perancang.

\section{d. Keluar}

Yaitu menu untuk keluar dari aplikasi AR ini.

\section{KESIMPULAN}

Kesimpulan "Rancang
Aplikasi Augmented Reality Katalog
Barang Elektronik Berbasis Android
menggunakan Unity 3D" yaitu:
Dengan dibuatkannya rancangan aplikasi Augmented Reality Katalog Barang elektronik berbasis Android dengan menggunakan Unity 3D ini maka customer dapat segera mendapatkan informasi barang yang dibutuhkan. Sesuai dengan hasil kuisoner dalam Uji Normalisasi Data, data berdistribusi normal jika probabilitas (asymp.sig(2failed) lebih besar dari 0,05 yaitu : Kualitas aplikasi $=0,306$, berdistribusi Normal dan Kepuasan Pengguna $=0,076$, berdistribusi Normal. Sedangkan dalam perhitungan Regresi Sederhana. Nilai Mean kepuasan pengguna 13,74 dengan Standar Deviasinya (SD) 2,181 dan nilai Mean Kualitas Aplikasi 13,53 dengan Standar Deviasi (SD) 2,280. Kooefisien Korelasi Kualitas Aplikasi dengan Kepuasan Pengguna 0,219 menunjukan hubungan yang kuat dan positif, dengan tingkat signifikansi 0,049 (dibawah0,05). R Square $\quad 0,219$ menunjukkan 21,9\% kepuasan pengguna dapat dijelaskan oleh kualitas aplikasi (sisanya 78,1\% dijelaskan oleh faktor lain-lain). Standard Error of the estimate 2,147 ledih kecil dari standar deviasi 2,181, maka dapat dikatakan bahwa model regresi yang ada cukup bagus dalam bertindak sebagai prediktor. $\mathrm{Y}=10,910+0,209 \mathrm{X}$ nilai signifikansi 0,000 . Dimana probabilitas kesalahan jauh dibawah 0,05, maka dapat dikatakan bahwa kualitas aplikasi secara nyata berpengaruh terhadap kepuasan pengguna.

\section{DAFTAR PUSTAKA}

1. Al-Bahra Bin Ladjamudin, 2005, dalam bukunya yang berjudul Analisis dan Desain Sistem Informasi. Penerbit Graha Ilmu

2. Azhar Susanto, 2013, Dalam bukunya yang berjudul Sistem Informasi Akuntansi. Bandung

3.. Darmawan, Erico. Pemrograman Dasar Berorientasi Objek C\#. INFORMATIKA, Bandung, 2016.

4. D. v. Krevelen and R. Poelman. 2010. A Survey of Augmented Reality Technologies, Applications and Limitations, Netherlands: The International Journal of Virtual Reality

5. Kaufmann, Hannes. 2012. Collaborative Augmented Reality in Education, Austria: The International Journal of Virtual Reality.

\section{INTERNET :}

Anonim. Android (Sistem Operasi). 2012.

https://id.wikipedia.org/wiki/Android_(si stem_operasi)

Anonim. Augmented Reality Indonesia. 2013.

http://augmentedrealityindonesia.com/. 